exists that human growth hormone actually works in this setting. The lay bodybuilding literature is full of testimonials, but as human growth hormone is as least as potent as an anabolic agent no doubt is left that growth hormone should be banned in sport. The use of human growth hormone in sport is promoted by the fact that as yet no practical method exists to detect that is in use in competition at the Olympic level. ${ }^{5}$ Several tests currently under study will hopefully be sufficiently robust for use at the Olympic games.

The use of human growth hormone to increase the height of children who are already of normal height should also be considered abuse. Another common form of use of human growth hormone outside the established indication is in its alleged action of reversing or slowing the effects of ageing. ${ }^{6}$ The quest for a "fountain of youth" is an age old dream, advertisements in print media and on the internet promote the use of human growth hormone or agents touted as increasing human growth hormone levels. Many of these agents are not growth hormone and do not lead to a sustained increase in concentrations of growth hormone. Although anabolic effects and changes in body composition have clearly been associated with the use of human growth hormone, in elderly people little or no evidence exists of an important positive functional effect on the processes of ageing. ${ }^{78}$

In addition to the lack of evidence for effectiveness of human growth hormone in these proposed uses, it causes side effects such as diabetes, carpal tunnel syndrome, fluid retention, joint and muscle pain, and high blood pressure. Many of these side effects were seen in studies that used much higher doses of human growth hormone than are now used in elderly people, so there is hope that studies using lower doses alone or in combination with modest doses of anabolic steroids may show a positive ratio of benefits to side effects. Well controlled clinical studies are needed to explore the potential uses of human growth hormone in elderly people and of its other potential uses as an anabolic agent.
Officially approved therapeutic uses of human growth hormone in selected countries

\begin{tabular}{|c|c|c|c|c|c|}
\hline Indication & $\begin{array}{c}\text { United } \\
\text { Kinadom }\end{array}$ & $\begin{array}{c}\text { European } \\
\text { Union }\end{array}$ & United States & Japan & Australia \\
\hline
\end{tabular}

\begin{tabular}{llllll}
\hline Growth hormone deficiency: & & & & \\
\hline \multicolumn{1}{c}{ In childhood } & $\mathrm{X}$ & $\mathrm{X}$ & $\mathrm{X}$ & $\mathrm{X}$ & $\mathrm{X}$ \\
\hline \multicolumn{1}{l}{ In adulthood } & $\mathrm{X}$ & $\mathrm{X}$ & $\mathrm{X}$ & & $\mathrm{X}$ \\
\hline AIDS wasting & $\mathrm{X}$ & $\mathrm{X}$ & $\mathrm{X}$ & $\mathrm{X}$ & $\mathrm{X}$ \\
\hline Renal failure & $\mathrm{X}$ & $\mathrm{X}$ & $\mathrm{X}$ & $\mathrm{X}$ & $\mathrm{X}$ \\
\hline Turner syndrome & $\mathrm{X}$ & $\mathrm{X}$ & $\mathrm{X}$ & $\mathrm{X}$ & \\
\hline Achondroplasia & $\mathrm{X}$ & $\mathrm{X}$ & & \\
\hline $\begin{array}{l}\text { Prader-Willi syndrome } \\
\begin{array}{l}\text { Poor growth in children small } \\
\text { for gestational age }\end{array}\end{array}$ & & & $\mathrm{X}$ & & \\
\hline \begin{tabular}{l} 
Idiopathic short stature \\
\hline
\end{tabular} & & & & & \\
\hline
\end{tabular}

However, the use of human growth hormone for indications that are not established is a waste of health funds and amounts to exploiting people and exposing them to unnecessary risk.

\section{Raymond L Hintz professor of pediatrics}

Stanford University, Stanford, CA 94305, USA (hintz@stanford.edu)

Competing interests: RLH has been a consultant to Eli Lilly and has received fees for speaking.

1 Raben MS. Treatment of a pituitary dwarf with human growth hormone. J Clin Endocrinol Metab 1958;18:901-3.

2 Fine RN, Kohaut MEC, Brown MD, Perlman AJ. Growth after recombinant human growth hormone treatment in children with chronic renal failure: report of a multicenter randomized double-blind placebo-controlled study. J Pediatr 1994;124:374-82.

Placebo-con et al. Clinical studies with recombinant-DNA derived methionyl-human et al. Clinical studies with recombinant-DNA derived methionyl-hu
growth hormone in GH deficient children. Lancet 1986;i:697-700.

growth hormone in GH deficient children. Lancet 1986;i:697-700.
Rennie MJ. Claims for the anabolic effects of growth hormone: a case of Rennie MJ. Claims for the anabolic effects of growth horm
the emperor's new clothes? Br J Sports Med 2003;37:100-5.

Sönksen PH. Insulin, growth hormone and sport. J Endocrinol 2001;170:13-25.

6 Rudman D, Feller AG, Nagraj HS Gergans GA, Lalitha PY, Goldberg AF, et al. Effects of human GH in men over 60 years old. $N$ Engl J Med 1990;323:1-6.

7 Marcus R, Butterfield G, Holloway L, Gilliland L, Baylink DJ, Hintz RL, et al. Effects of short term administration of recombinant human growth
hormone to elderly people. J Clin Endocrinol Metab 1990;70:519-27.

8 Blackman MR, Sorkin J, Münzer T, Bellantoni M, Busby-Whitehead J, Stevens T, et al. Growth hormone and sex steroid administration in healthy aged women and men: a randomized controlled trial. JAMA 2002;288:2282-92

\title{
Refeeding syndrome
}

\section{Is underdiagnosed and undertreated, but treatable}

$\mathrm{R}$ efeeding syndrome was first described in Far East prisoners of war after the second world war.' Starting to eat again after a period of prolonged starvation seemed to precipitate cardiac failure. The pathophysiology of refeeding syndrome has now been established. ${ }^{2}$ In starvation the secretion of insulin is decreased in response to a reduced intake of carbohydrates. Instead fat and protein stores are catabolised to produce energy. This results in an intracellular loss of electrolytes, in particular phosphate. Malnourished patients' intracellular phosphate stores can be depleted despite normal serum phosphate concentrations. When they start to feed a sudden shift from fat to carbohydrate metabolism occurs and secretion of insulin increases. This stimulates cellular uptake of phosphate, which can lead to profound hypophosphataemia. ${ }^{3}$ This phenomenon usually occurs within four days of starting to feed again.
Phosphate is necessary for the generation of adenosine triphosphate from adenosine diphosphate and adenosine monophosphate and other crucial phosphorylation reactions. Serum phosphate concentrations of less than $0.50 \mathrm{mmol} / \mathrm{l}$ (normal range $0.85-1.40 \mathrm{mmol} / \mathrm{l}$ ) can produce the clinical features of refeeding syndrome, which include rhabdomyolysis, leucocyte dysfunction, respiratory failure, cardiac failure, hypotension, arrhythmias, seizures, coma, and sudden death. ${ }^{4}$ Importantly, the early clinical features of refeeding syndrome are non-specific and may go unrecognised.

Refeeding syndrome can occur with parenteral as well as enteral feeding. In the United Kingdom patients with anorexia nervosa, cancer, alcoholism, and some patients after operations are known to be at risk of refeeding syndrome. ${ }^{6}$ However, other groups, such as patients with neurological dysphagia who are being 
fed through nasogastric or percutaneous endoscopic gastrostomy tubes, may also be at risk.

Understanding of refeeding syndrome and its treatment is limited among general physicians and surgeons. Many patients at risk of refeeding syndrome are not treated on specialist nutrition units. Measurement of serum phosphate may not be done in patients at risk, and when phosphate is measured the importance of grossly abnormal results may not be recognised. The other barrier is a lack of consensus on treatment. Intravenous phosphate is required as oral supplementation is inadequate. Previously recommended regimens for treatment of severe hypophosphataemia have been developed mainly from experience in treating small numbers of patients in intensive care settings. ${ }^{7}$ Typically regimens recommend multiple infusions based on weight, with frequent monitoring of serum phosphate, but these complex regimens may be impractical on general wards. Ideally a treatment regimen for refeeding syndrome would not require monitoring blood tests more often than daily, would not require adjustment for weight, and would provide an adequate dose of phosphate.

Results of such a regimen have recently been published. ${ }^{8}$ Thirty patients with refeeding syndrome, normal renal function, and a phosphate concentration of less than $0.50 \mathrm{mmol} / \mathrm{l}$ were treated with $50 \mathrm{mmol}$ intravenous phosphate over 24 hours $(500 \mathrm{ml}$ Phosphates Polyfusor, Fresenius Kabi, Warrington, United Kingdom). This treatment was effective; 93\% (28/30) achieved a serum phosphate concentration of $0.50 \mathrm{mmol} / \mathrm{l}$ or more after four days. Importantly, five patients required further phosphate as severe hypophosphataemia recurred after initial correction. The treatment seemed safe; no patient developed renal failure, although three patients developed mild transient hyperphosphataemia and four asymptomatic hypocalcaemia. Importantly, all patients were managed on general wards. Although this study is uncontrolled, it is the largest published series of the treatment of severe hypophosphataemia due to refeeding syndrome.

Treatment of refeeding syndrome can be helped by the input of hospitals' nutrition teams. Dieticians and nutrition nurses can help in identifying malnourished patients at risk of developing refeeding syndrome. When these patients require artificial feeding (enteral or parenteral), this should be started at a reduced calorific rate (25-50\% of estimated requirements) to reduce the risk of refeeding syndrome developing. Serum phos- phate, magnesium, calcium, potassium, urea, and creatinine concentrations should be measured before feeding and repeated daily for four days after feeding is started. When hypophosphataemia occurs it should be corrected in addition to other electrolyte abnormalities, such as hypokalaemia and hypomagnesaemia. Feeding can be continued. If after 24 hours the serum phosphate concentration remains low or falls subsequently then further phosphate should be administered.

No randomised controlled trials of treatment for refeeding syndrome have been performed, and the optimal regime therefore remains to be determined. In addition the exact degree of hypophosphataemia requiring treatment remains to be determined, although most experts on nutrition would recommend treatment of hypophosphataemia with measurements of 0.32-0.50 mmol. Randomised controlled trials of the treatment of refeeding syndrome, with clinical end points such as survival, are therefore needed. The current priority is to improve awareness of refeeding syndrome among general physicians and surgeons and to convince them of its importance. Many doctors remain unconvinced of the importance of treating hypophosphataemia, while in contrast accepting the need to treat other electrolyte deficiencies such as hypokalaemia and hypomagnesaemia. With further liaison between hospital nutrition teams and ward staff and the use of an adequate treatment regimen, it may be possible to improve the prognosis of this currently underecognised and undertreated group substantially.

Stephen D Hearing consultant gastroenterologist

Department of Gastroenterology, Staffordshire General Hospital, Weston Road, Stafford ST16 3SA

(stephen.hearing@msgh-tr.wmids.nhs.uk)

Competing interests: None declared

1 Schnitker MA, Mattman PE, Bliss TL. A clinical study of malnutrition in Japanese prisoners of war. Ann Intern Med 1951;35:69-96.

Crook MA, Hally V, Panteli JV. The importance of the refeeding syndrome. Nutrition 2001;17:632-7.

Crook M, Swaminathan R. Disorders of plasma phosphate and indications for its measurement. Ann Clin Biochem 1996;33:376-96.

4 Silvis SE, Paragas PD Jr. Paraesthesias, weakness, seizures, and hypophosphataemia in patients receiving hyperalimentation. Gastroenterolog 1972;62:513-20.

5 Weinster RL, Krumdieck CL. Death resulting from overzealous total parenteral nutrition: The refeeding syndrome revisited. Am J Clin Nutr 1980;34:393-9.

6 Cumming AD, Farquhar JR, Bouchier IAD. Refeeding hypophosphataemia in anorexia nervosa and alcoholism. BMJ 1987;295:490-1.

Perreault MM, Ostrop NJ, Tierney MG. Efficacy and safety of intravenous phosphate replacement in critically ill patients. Crit Care 1997;31:683-8. 8 Terlevich A, Hearing SD, Woltersdorf WW, Smyth C, Reid D, McCullagh E, et al. Refeeding syndrome: effective and safe treatment with phosphates polyfusor. Aliment Pharmacol Ther 2003;17:1325-9.

\section{Pre-eclampsia and the risk of cancer}

\section{Several studies suggest a decreased risk-except this one}

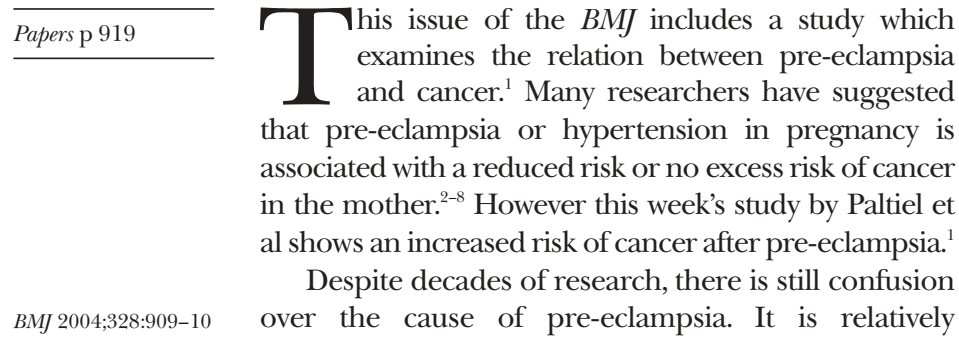

common, affecting $3-5 \%$ of pregnancies, and is a leading cause of morbidity and mortality both in the mother and unborn child. ${ }^{9}$ Several observational studies in European and North American populations have examined the relation between pre-eclampsia (or hypertension) in pregnancy and cancer. ${ }^{2-8}$ Unfortunately some were based on a small number of cancers in the pre-eclampsia group, not all adjusted for known confounders, and the length of follow up varied. Most 